\title{
A IMPORTÂNCIA DA AFETIVIDADE NA RELAÇÃO ENTRE PROFESSOR E ALUNO DURANTE O PROCESSO DE ALFABETIZAÇÃO NA EDUCAÇÃO INFANTIL
}

\author{
Célia Maria Ferreira Prianti ${ }^{1}$ \\ Giovana Filomena dos Santos ${ }^{2}$ \\ Juliane Rocha de Moraes $^{3}$
}

\begin{abstract}
Resumo: O presente trabalho tem a função de focar a interação entre professor e aluno e o papel da afetividade no desenvolvimento no processo da alfabetização. A partir do referencial teórico abordaremos a formação docente, formação cognitiva da criança, sua vivência social durante a alfabetização. Quando a criança entra na alfabetização, deve levar em consideração os aspectos e procedimentos anteriores, que são tão necessários e que pode contribuir muito para uma alfabetização mais tranquila e positiva. Para Emília Ferreiro, a construção do conhecimento da escrita tem uma conexão com o individual e também com a interação social na escola, ou fora dela. A construção desse conhecimento ocorre por meio das sequências de hipóteses.
\end{abstract}

Palavras-chave: Afetividade; Aprendizagem; Professor; Aluno.

\footnotetext{
1 INESP/RECOVALE, Brasil. E-mail: cfprianti@hotmail.com.

2 INESP/RECOVALE, Brasil. E-mail: mairmoris@gmail.com.

3 INESP/RECOVALE, Brasil. E-mail: juli04.rocha@gmail.com.
} 